\title{
MEASURING THE INTEGRATION OF SOCIAL AND ENVIRONMENTAL MISSIONS IN HYBRID ORGANIZATIONS
}

\author{
Edward N. Gamble \\ Montana State University, USA
}

\author{
Simon C. Parker \\ Ivey Business School, Canada and University of Aberdeen, UK
}

Peter W. Moroz

University of Regina, Canada

\begin{abstract}
This paper introduces a new typology and associated measure of social and environmental mission integration (SEMI) by conceptually framing a feature of hybrid organizations - the degree of integration of their revenue model and social-environmental mission. The SEMI measure is illustrated using a hand-collected sample of 256 North American Certified B Corporations. We explore the heterogeneity of SEMI scores by identifying external-facing correlates and demonstrate non-congruence with Certified B Corporation's audit results. Overall, these finding advance our knowledge of hybrid organizations and how they balance their socialenvironmental missions with their economic objectives.
\end{abstract}




\section{Introduction}

Hybrid organizations combine activities, structures, processes, meanings, and organizational forms from different fields (Battilana \& Lee, 2014; Jay, 2013) and are thus guided by multiple institutional logics (e.g. state, professional, community, or religious logics) (Thornton, Ocasio, \& Lounsbury, 2012). They represent a large and diverse constituency of contexts and forms public, nonprofit, private and other emerging forms - that engage in a wide range of economic and non-economic missions (Austin, Stevenson, \& Wei-Skillern, 2006; Battilana \& Lee, 2014). For example, hybrid organizations can range from innovative startups that seek to address the grand challenges of society, to larger ventures that simply wish to provide a better environment for their workers, contribute to their communities, or lessen their environmental footprint (Doherty, Haugh \& Lyon, 2014). Yet hybrid organizations are often faced with multiple and conflicting tensions arising from their organizational form (Davies \& Doherty, 2018; Doherty et al., 2014; Ebrahim, Battilana, \& Mair, 2014; Haigh, Walker, Bacq, \& Kickul, 2015; McMullen \& Warnick, 2016).

One important tension facing some hybrids is the integration of social and environmental (S\&E) missions with commercial missions (Emerson, 2003; Santos, Pache \& Birkholz, 2015). Many hybrid organizations face a challenge in choosing business models that tradeoff social and environmental (S\&E) objectives with profits for their owners. This challenge can be experienced differently in hybrids based on the degree to which their S\&E missions are integrated with their commercial missions. Hybrid organizations are very heterogeneous (Battilana et al., 2012), as are the business models they utilize (Thompson \& MacMillan, 2010; Zott \& Amit, 2007, 2008, 2010). Even with the present article's focus on commercial organizations that have a social or environmental mission, diversity among these organizations is pronounced and we still know 
relatively little about the degree of integration of their business models that encapsulate these tradeoffs.

Attempts to categorize hybrid contexts may be one way of tackling such heterogeneity, revealing new underlying structures. The value of typologies has been recognized in some recent work on hybrid organizations (Dyllick \& Muff, 2016; Ebrahim, et al., 2014; Jaeger-Erben, Ruckert-John, \& Schafer, 2015; Peredo, Haugh, \& Mclean, 2017; Tracey \& Stott, 2017; Wilson \& Post, 2013; Zahra et al., 2009). Yet business model typologies of hybrids are likely to be especially valuable in environments where the nature of hybrid businesses are often hidden to internal and external stakeholders (Lautermann, 2013). In such cases, the identification of different types can facilitate a clearer understanding of who hybrids are and what they do. For example, in an important recent contribution Ebrahim et al. (2014) proposed a two-category typology comprising 'integrated' and 'differentiated' types. The former has social missions that are integrated with their revenue models, while the latter has social missions that are separable from their revenue models. Ebrahim et al. (2014) explored what forms of governance are relevant for each type of hybrid, to help them avoid 'mission drift' and sustain their existence.

The present article extends this work by noting that the two types proposed by Ebrahim et al. (2014) occupy the end points of an underlying continuum of business model integration. What is missing is an intermediate position, occupied by business models which are 'partially' integrated. We argue (and find evidence to support the notion) that there are numerous commercial organizations that have a social or environmental mission, and which are not purely integrated or differentiated. Thus, one contribution of this paper is to propose a three-type typology, comprising 'integrated', 'partially integrated' and 'differentiated' types. We contend that this makes for a more complete typology which better characterizes the hybrid space. 
In fact, this extended typology is just one of several contributions made by the present paper. A second contribution is the development of an empirically operational measure, which corresponds to the three types identified in the new typology. Specifically, we develop a novel Social and Environmental Mission Integration (SEMI) index to assess the degree of integration of a hybrid organization's S\&E mission with its revenue model. As a third contribution, we provide an empirical illustration of this index by calculating SEMI values for a specific sample of hybrid organizations: B Corps. While not a truly comprehensive or representative sample of hybrids, B Corps are an increasingly visible subgroup of hybrid organizations (Gehman \& Grimes, 2016; Moroz et al., 2018; Wilson \& Post, 2013). This sample frame provides a consistent basis for sampling firms, since it comprises only those firms viewed as pursuing both profit and purpose (hybrid activities). At the same time, it also comprehends considerable heterogeneity of the S\&E configurations observed, in terms of company size, age and industry sectors.

Fourth, after describing the hand-collected sample of 246 B Corps and coding methods, we report SEMI index values and perform an econometric analysis of covariates that are related to them - including B Lab's audit 'B scores'. This generates a rich set of novel findings that we go on to interpret and discuss in the closing section of this article. We believe that this may help scholars to better understand hybrid activities by bringing further attention to the complexity involved with how hybrids distinguish themselves from competitors regarding their own ethical and/or competitive positioning (Muñoz \& Kimmitt, 2018). For instance, our findings seem to indicate that developing integrated S\&E and economic missions may be difficult, and that B Corp certification may be an appealing alternative way of signaling legitimacy and reputation to important stakeholders. 
The paper proceeds as follows. First, we briefly review prior literature on hybrid organizations and business models and introduce our typology. We then describe the sample of B Corps, the coding and construction of the SEMI index, and the estimation methodology. Next, we present the results about the frequency of SEMI values and variables associated with them. Finally, we provide a discussion of the typology and empirical findings and draw out implications for scholars working in the field.

\section{Hybrid organizations, business models and a typology}

\section{Hybrid organizations}

Hybrid organizations that engage in $\mathrm{S} \& \mathrm{E}$ missions make a unique identity claim (Zuckerman, 1999): to generate both economic returns for owners and non-economic returns for stakeholders and owners (Santos, 2012). Research has shown that tensions may manifest across individual, organizational and environmental levels from the operation of dissonant, paradoxical or conflicting functions or activities (Doherty et al., 2014; Thornton, Ocasio \& Lounsbury, 2012). For example, tensions may arise from mission drift, governance strain, competing demands from different stakeholders, difficulties in scaling, and limited exit opportunities (Battilana \& Lee, 2014; Ebrahim et al., 2014; Haigh \& Hoffman, 2012; Mair et al., 2015; Pache \& Santos, 2013; Negro, Hannan \& Rao, 2010).

Numerous studies discuss the relevance of hybridity to the fields of social enterprise (Doherty et al., 2014), social entrepreneurship (Dacin, Dacin \& Matear, 2010), social change (Hoffman, Badiane, \& Haugh, 2012; Kolk \& Lenfant, 2016) and economics (Ménard, 2004). Researchers across this disciplinary spectrum have surfaced numerous interesting questions relating to characteristics of hybrid types, their legitimacy and competitive advantage (Dart, 
2004; Markides \& Charitou, 2004; O’Neil \& Ucbasaran, 2016) - as well as new organizational and legal forms suitable for hybrid organizing (Hiller, 2013; Wilson \& Post, 2013).

The boundary spanning activities of hybrids means that the business models they employ may not conform well with known venture categories (Durand \& Paolella, 2013; Hahn \& Ince, 2016; Rawhouser, Cummings \& Crane, 2015; Paolella \& Durand, 2016). One pressing question is whether hybridity can be unpacked into more specific types (Corbett \& Katz, 2017; Weick, 2012) and how each of these types adopt strategies to overcome the challenges of creating S\&E impact as 'ends', while still pursuing profits as 'means' - or vice versa.

\section{Hybrid organization typologies and business models}

Typologies are an important method for understanding, defining and explaining the nature of organizational phenomena by modeling observations about forms, behaviors and processes (Doty \& Glick, 1994). They can play a significant role in examining the causal relationships between an organization's structure, strategy, context and environmental consistency (Fiss, 2011). The term 'typology' refers to "conceptually derived interrelated sets of ideal types...each of which represent a unique combination of the organizational attributes that are believed to determine the relevant outcome(s)" (Doty \& Glick, 1994: 232). As such, typologies are a critical tool in theory development, but are not always theory in and of itself (Bacharach, 1989). Typologies also differ from the term 'classification', which consists of discrete sets that are clear and mutually exclusive (Woodward, 1965). They align more closely with the term 'category' in that audiences often reduce the complexity of organizations into recognizable or prototypical attributes to make judgements about their membership and to bring order to organizational existence, legitimacy, and interactions within the market place (Durand \& Khaire, 2017). 
In contrast, prior literature on hybrids has paid less attention to the role of business models in differentiating hybrids into ideal types based on observable attributes. According to Teece (2010: p 179), "a business model articulates the logic, the data, and other evidence that support a value proposition for the customer, and a viable structure of revenues and costs for the enterprise delivering that value. In short, it's about the benefit the enterprise will deliver to customers, how it will organize to do so, and how it will capture a portion of the value that it delivers". That is, business models can help articulate how value - both economic and noneconomic - is created and delivered to audiences when complex demands are placed upon a firm, such as a hybrid organization (Paolella \& Durand, 2016). Thus, business models could directly articulate how hybrid organizations manage the tradeoffs between economic (i.e. revenue) and non-economic (e.g. S\&E) missions. In view of the challenges hybrids face in managing these tradeoffs, they would seem to be an ideal basis for framing a typology.

\section{A comprehensive business model-based typology of hybrid organizations}

As explained earlier, the degree to which the social and/or environmental mission is integrated or separable from the financial mission of an organization varies substantially across organizations. To make some sense of this heterogeneity, Ebrahim et al. (2014) proposed a simple binary distinction: one type of organizations has 'integrated' social missions, while the other has 'differentiated' social missions. One can imagine these two types being situated at extreme ends of an underlying continuum registering different degrees of integration of social and financial missions. This section adds to the two types of Ebrahim et al. (2014) a third type which lies in an intermediate position on the continuum, and which we connote as 'partially integrated'. Consider now each of these types in turn. 
First, if the revenue model clearly drives the $\mathrm{S} \& \mathrm{E}$ mission(s) and is inseparable from a hybrid's revenue model, making the business model dependent upon the mission(s), it may be classified as integrated. Integrated hybrids can be identified by answering the question: 'when considering what value is created, how it is created and who it is created for, is the value proposition of the business model clearly driven by the dependence of the revenue model upon the S\&E mission?' If yes, then it would be an integrated hybrid. According to Durand and Paolella (2013, p. 1101), “audiences navigate better across markets and social worlds when categories are clearly marked and unambiguous." Indeed, prior evidence has found that audiences penalize firms with ambiguous identities (Hsu, Hannan, \& Koçak, 2009; Negro \& Leung, 2013). Thus, an integrated business model may preclude the need for audiences to actively search for signals pertaining to a hybrid's S\&E goals, as the questions why, how and for whom value is created is revealed through an integrated business model. This may help to confer distinctiveness on the firm as audiences may easily place it within a single category: they do not need to expend time themselves calibrating social impact as the business model itself reveals many of its hidden characteristics (Dobrev et al., 2001; Hannan et al., 2007).

For example, Colorado-based Namasté Solar creates benefits for customers who seek to develop and utilize sustainable energy sources. The business model of this hybrid would simply not exist without the S\&E mission: the two are bound up together and inseparable from each other. New York-based Greyston Bakery affords another example. The value proposition of this hybrid is that it generates employment opportunities for disadvantaged populations. This mission is integrated into the operations of its business and is observed by the customers who patronize it. Hence Greyston Bakery's revenue model cannot be detached from its S\&E activities. Thus, Greyston Bakery and Namasté Solar are both integrated hybrid types. They both clearly signal 
the dependence of the revenue model upon the S\&E mission of the business model when articulating what value is created, how it is created and for whom is it created.

Second, a partially integrated category is one where the hybrid's S\&E efforts are clearly aligned with the revenue model, but the revenue model is not dependent upon the S\&E mission(s). Partially integrated hybrids can be identified by answering the question: 'when considering what value is created, how it is created and who it is created for, is the value proposition of the business model enhanced by an alignment with the revenue model and the S\&E mission(s) but the revenue model is not dependent upon the S\&E mission(s)?' If yes, then it is a partially integrated hybrid. In this case, while the hybrid's identity may benefit from the alignment of revenue model and mission, they may yet be perceived as constituting two separable value propositions, potentially signaling more than one identity to audiences. As the revenue model is aligned with, but not obviously directly related to the $\mathrm{S} \& \mathrm{E}$ mission, the $\mathrm{S} \& \mathrm{E}$ efforts must be defined using accepted norms, routines and strategies that audiences and institutions will identify with their own value systems as 'real' characteristics (Durand \& McGuire, 2005; Porac, et al., 1995; Vergne \& Wry, 2014).

Examples of the partially integrated business model type include TheGreenOffice.com, which is an office equipment provider that also researches and ranks the sustainable production value of various office equipment products. While bundling the sustainability of furniture supply chains with furniture sales is important to some customers and enhances the value of the economic activities, the company does not only sell sustainable furniture. Thus, the economic and non-economic value propositions may be aligned to recombine resources and create more value (office furniture seller + ranking of sustainable furniture supply chains); but they are ultimately separable from each other. Another example is North Carolina-based Rain Water 
Solutions. This company manufactures above- and below-ground rainwater harvesting systems and features a 65-gallon rain barrel design made from recycled plastics. Through the production and sale of their products, they also engage with clients on water quality and conservation issues. Obviously, water conservation aligns well with the production of rainwater harvesting equipment and adds to its overall value; yet the business model can in principle survive the removal, or dilution, of the S\&E component and still be viable. Once again, the primary economic value proposition of the business model is providing solutions to storm water runoff; the storage product is stand-alone. It is conceivable that the company could produce rainwater harvesting systems without any S\&E mission beyond its commercial activities.

Third, a non-integrated (or 'differentiated') category is one where the revenue model is not aligned with, and is independent of, the S\&E mission(s). Non-integrated hybrids can be identified by answering the question: 'when considering what value is created, how it is created and who it is created for, is the value proposition of the business model independent of and unaligned with the S\&E mission(s)?' If yes, then the hybrid falls into the non-integrated category. While the efforts of a non-integrated category do appear to be socially beneficial, the various missions are independent of and not substantially or obviously aligned with their revenue model in a way that coherently illuminates what value is being created, who exactly value is being created for and how it is being created.

For example, California-based Fireclay Tile is a company devoted to making beautiful and durable handmade high-quality tiles 'with soul' to drive their revenue model. Fireclay Tile also seeks to be a 'better' company by: donating $1 \%$ to a different charity partner every year; using recycled goods whenever possible; operating with financial transparency for all team members; and eliminating commissions to instead incorporate a 'fairer' company-wide bonus 
plan. While these efforts would certainly appear to be beneficial, the various S\&E missions are independent of and not clearly aligned with their revenue model. That is, one need not design and sell tiles to donate to charities or recycle - or vice-versa. Also fitting into this category are organizations whose CSR efforts are simply 'bolted on' to their business (Laufer, 2003).

In principle, it is straightforward for a researcher to inspect the business model of a given organization and assign it to one of the three categories described above. We now go on to perform such a task for a specific sample of organizations, described next.

\section{Data and Methods}

To illustrate our hybrid business model typology empirically, we study a specific subset of hybrid organizations - Certified B Corporations (B Corps). B Lab is a U.S. not-for-profit organization that acts as a third-party external auditor of social and environmental reporting (André, 2012). It grants the designation of 'Certified B Corporation' to organizations worldwide which meet or exceed B Lab's standards. B Lab aspires to be a catalyst for corporate-directed social change and a resource for organizations that support its mantra 'to redefine success in business' (Reiser, 2011). To this end, the B Lab certification and the B Lab audit, called the 'B assessment', provides an independent, public 'B score' that ranges from a minimum certification threshold of 80 to a maximum of 200 . The B score is derived from impact measurements taken across four different categories: Environment, Workers, Community and Governance. B Lab claims that behind their B Corporation certification is a framework that helps leaders of organizations improve aspects of governance and employee engagement, to have a more positive impact on the local and global community and environment. 
Even a cursory scan of the organizations within the B Corp category reveals a wide variety of industries, business models and S\&E activities. Given this variety, we suspect that the relationship between B Corps' S\&E activities and their revenue models will vary. For example, some B Corps, such as Lunapads - natural feminine care products that divert other nonrecyclable products from landfills and that supports women globally by providing access to sanitary products for those in need - may have revenue models that are dependent on and directly benefit the target of their S\&E mission. Alternatively, B Corps, such as Uncommon Goods - an online artisan and craft boutique that provides back stories of all the craftspeople and allows customers to donate to a nonprofit organization of their choice with each purchase seems to have a revenue model that does not directly benefit the mission and is separable from its S\&E efforts.

In what follows, we first describe the sample and explain how firms are assigned to one of the three types. We then define a dependent variable and several explanatory variables, which are used to relate those types to firm-level characteristics, to shed light on the factors associated with different degrees of business model integration.

\section{Sample}

Between August 2014 and August 2015, the authors contacted all 918 of the then-certified privately held B Corps in North America by telephone to determine their willingness to participate in a research study. Following a pilot study involving C-level managers at ten wellknown B Corps, the research team developed an informational video and project webpage, which described the essence of the research project. This was emailed to a CEO, CFO or COO in every North American B Corp during the data collection period, along with a link to a 10-minute 
survey. The survey included questions on: contact information, years in business, industry sector, fiscal year end, currency used to present financial results, revenue data from the most recent four years, and employee figures for the most recent four years (2011-2014). A total of 35 C-level executives (either chief executive officers, chief financial officers and chief operational officers) requested a telephone conversation prior to filling out the survey. The phone conversations ranged in time from 30-90 minutes in length.

In total 140 survey responses were received from the first wave of requests. Five months later we sent out a second wave to those who had not responded to the first request. We received 116 surveys on the second pass with 14 telephone conversation requests. In total we elicited responses from 256 B Corps (hereafter called 'firms'), giving a response rate of nearly $28 \%$. Of the respondents, $85 \%(n=218)$ were based in the United States, $13 \%(n=34)$ were based in Canada, and the remaining 2\% $(\mathrm{n}=4)$ were in Mexico.

The database was supplemented with the audited B Lab scores ('B scores' hereafter) for each firm, taken directly from B Lab's website https://www.bcorporation.net/. Since 2012, B scores have been calculated as the sum of four major components: Governance, Worker, Environmental and Community. We also gathered data on the year each firm was certified as a B Corp, geographical location and organizational form. Each organization was classified either as a 'benefit corporation', a corporation, a limited liability company, a limited partnership, or 'other'. In the sample, only $6 \%$ of respondents were registered as benefit corporations. Once the data was gathered it was collated, checked and cleaned by a supervised research assistant and prepared for statistical analysis. 


\section{Assigning types and the dependent variable SEMI}

Assignment of each B Corp to one of the three types took four months and involved the participation of all three members of the author team. Three sessions were conducted in which the independent researchers reviewed the B Lab pages, direct company web pages and linked content on each of the 256 firms identified in the sample. As the sampling technique was predetermined by the organizations that responded to the survey, and the coding protocols limited to conformity with the three questions given in the next section, coding analysis kits (such as Atlas.ti) were deemed inappropriate. This content analysis technique thus allowed for each researcher to engage the parameters provided by our business model typology to sort each company into an 'ideal type'; the approach was evaluative, not inductive (Thomas, 2006). Regarding the clarification and reliability of the typology constructs and team coding processes (see Saldana, 2009), on the first pass there were only 4\% (11 cases) where the coders all disagreed on the categorizations and $29 \%$ (75 cases) where only two coders disagreed. The second round of coding was done by having each coder produce an argument for their categorization, leading to a 'stick to your guns', or 'concede' outcome. Of these, only 35 were left unresolved, leading to a third round of coding which involved oral discussion and presentation of evidence by each researcher, ultimately leading to accord on the categorization of the variable against the entire data set in full agreement with the constant comparison approach (Glaser, 1965).

To map types into firm characteristics, a dependent variable called 'SEMI score' was constructed by coding values of 0,1 and 2 to firms with non-integrated, partially integrated and integrated hybrid business models, respectively. Hence higher values of the SEMI score correspond to S\&E missions that are more integrated/aligned with the revenue model. 


\section{Explanatory variables}

The empirical exercise not only reports frequencies for each SEMI type, but also seeks to predict SEMI scores using firm-level characteristics. The explanatory variables used for this purpose are explained now.

First, we measured firms' latest B scores prior to the completion of the data collection exercise, and their disaggregated component scores under the Workers, Governance, Environment, and Community categories. These data were extracted from the bcorporation.net website. The purpose of regressing the SEMI scores on these independent variables is to explore the relationship between them and to gauge the extent to which the SEMI is capturing something distinct from B scores. Second, we obtained, directly from the firms, survey data on the age of the firm in 2015, the industry sector of the firm, prior revenue and employment growth rates of the firm, and whether the firm was a benefit corporation. Industry dummies were coded by a research assistant and verified independently by the authors. The most frequently occurring industry sectors were 'Consulting, HR and Marketing Services' (23\%); 'Food and Drink' (19\%); 'IT, Software and Web Design' (12\%); 'Financial Services' (12\%); and 'Light Manufacturing, Crafts and Apparel' (11\%). Third, other independent variables include whether the firm was based outside the US; the year the firm was certified (centered on 2000); and the age of the firm when it became certified.

Knowing how these independent variables are related to the dependent variable holds out the promise of deepening scholarly understanding of which types of enterprise are most likely, within a given context, to select an integrated business model. Insights of this kind can in principle extend and enhance existing efforts to categorize firms, by augmenting first- and third- 
party category claims with a valuable new source of information. For example, if there is a high correlation between the SEMI and B scores, one may infer that B scores already capture a large amount of social mission integration content. But if on the other hand the correlation is modest, then the two values are capturing largely different outcomes, enhancing the information content of the SEMI measure.

\section{INSERT TABLES I \& II ABOUT HERE}

Table I presents a summary of the descriptive statistics, and Table II presents the correlation matrix. Table I reveals that the modal SEMI category, accounting for $63 \%$ of cases, is 0. This striking result suggests that integrated models are not the norm, even among B Corps. Most B Corps, it seems, have sought and obtained B Lab certification yet possess S\&E missions which are not even aligned with, or related to, their primary business practices. Only $25 \%$ of B Corps have integrated business models, with the remaining $12 \%$ having partially-integrated business models.

Table I also summarizes information about the B scores of the firms in the sample. The minimum B score is 80 , as stipulated by B Lab; the sample mean is nearly 30 points above this threshold. The B Governance score has the lowest sample mean and the B Community has the highest sample mean of the various B score components. The mean firm age is just under 13 years, though this hides a lot of variation: one firm is as old as 67 years, seeking B Lab certification long after its foundation. The firms in the sample demonstrate robust annual revenue and employment growth rates of $27 \%$ and $17 \%$, respectively. Some $84 \%$ of them are based in the USA; only $6 \%$ of them incorporated using the legal form 'benefit corporation'. 
Table II presents pairwise correlation coefficients. It can be seen at once that the correlation between SEMI values and B scores is positive and statistically significant. Yet at 0.25 , it is moderate in size, suggesting that the two variables are capturing distinct outcomes. A similar correlation coefficient is found between SEMI and B Env (the environmental component of the B score), suggesting that B Corps which score highly on the environment component of their B Lab audit tend to have more integrated business models - compared with B Corps which score highly on other components of the audit. There is no significant correlation between SEMI and firm growth measures, which is perhaps not too surprising since financial performance outcomes should not necessarily depend on SEMI. Younger firms, and those found in some industry sectors like education and light manufacturing, also tend to have higher SEMI values on average.

Most of the other correlation coefficients are numerically small, apart (unsurprisingly) from the individual components of the B scores with the overall B score; and 'year certified' with B score: newer B Corps tend to have lower B scores on average. There are no indications of collinearity between the variables used in our econometric specifications, which are described next.

\section{Econometric methods}

Our conceptual analysis conceived of an underlying continuum of business model integration, on which three discrete types are located. The empirical counterpart to this conceptual framework is a discrete dependent variable, SEMI, taking values 0,1 and 2 that correspond to firms coded as non-integrated, partially integrated and integrated. These three discrete values can be placed on an underlying, unmeasured empirical continuum of business model integration. Since the three discrete values of SEMI are ordered, the appropriate econometric model is an ordered probit (Greene, 2012). 
Ordered probit is a discrete dependent variable econometric model, not a regression. The dependent variable in a traditional regression model is a continuous variable which is distributed over the real line. In contrast, ordered probit deals with a distinct number of types, ordered on an underlying and unmeasured continuum. It is therefore consistent with the conceptual analysis of the typology proposed earlier. The ordered probit models we estimate relate SEMI values to the independent and control variables. All estimations and post-estimation computations are performed in STATA 11.

\section{Results}

The main results are presented in Table III. Model (1) of Table III takes B Score as the main independent variable; this is replaced by the four component scores in Model (2). Both models exhibit reasonable explanatory power, as measured by the pseudo- $\mathrm{R}^{2}$ and Wald statistics. Table IV presents the predicted probabilities of a given firm being in one of the three SEMI categories, for various values of the key explanatory variables. In Table IV, the mean values of every independent variable except for one (e.g. B score in Panel A of this table) are applied to every firm; the values of the one exception are then varied to see how the probabilities of a firm being in a different SEMI category change. Further details and examples appear below.

INSERT TABLES III \& IV ABOUT HERE

The most notable results are as follows. First, the coefficient on the B score in Model (1) of Table III is positive and highly significant, confirming in a multivariate setting what was observed for the pairwise correlation in Table II. That is, higher B scores are on average associated with more integrated S\&E missions. Panel A of Table IV computes predicted 
probabilities of a firm being in one of the three SEMI categories for various values of the B score, ranging from the minimum of 80 up to 140 . As can be seen, there is a substantial increase in the probability of being in the integrated SEMI category as B scores increase above 100. For example, Panel A of Table IV shows that as B scores increase across the sample, from 80 to 140, the probability that a firm has a non-integrated business model (SEMI $=0$ ) drops from $81 \%$ to $41 \%$. At the same time, the probability that a firm has an integrated business model (SEMI=2) rises from $10 \%$ to $42 \%$.

Second, Model (2) of Table III identifies the two B score components which seem to be driving this result. These are 'B Env' (B score for environment) and 'B Com' (B score for community). Higher values of these outward-facing component scores are associated with more integrated social missions. In contrast, firms can score highly on B Lab's worker and governance audit criteria while having non-integrated business model types. Thus, these last two B Lab criteria may enable firms to 'bolt on' CSR activities that are unrelated to their business models and attain B Lab certification without truly integrating S\&E missions into their revenue model.

Panels B and C of Table IV present the predicted probabilities for B Env and B Com. These entries demonstrate sizeable effects on SEMI values from environmental and community B scores. There are some interesting additional nuances as well: for example, Panel B shows that as environmental B scores increase across the sample, from 0 to 75 , the probability that a firm has a non-integrated business model (SEMI $=0$ ) drops from $78 \%$ to $23 \%$. At the same time, the probability that a firm has an integrated business model (SEMI $=2$ ) rises from $12 \%$ to $64 \%$. Partially-integrated business models (SEMI=1) are rather insensitive to changes in environmental B scores, partly reflecting the low sample proportions of this type of firm. A similar, but more muted pattern, is observable in Panel C regarding community B scores. This panel shows that as 
community B scores increase across the sample, from 0 to 75 , the probability that a firm has a non-integrated business model (SEMI=0) drops from $82 \%$ to $43 \%$. At the same time, the probability that a firm has an integrated business model (SEMI $=2$ ) rises from $10 \%$ to $42 \%$.

Third, firm age maps negatively and significantly into SEMI values (both columns of Table III). That is, older firms are significantly more likely than younger firms to have nonintegrated social missions. Older firms may find it harder to develop an integrated business model if they were founded prior to B Lab's emergence. For example, their business models may be hard to change given strong imprinting effects, inertia and adjustment costs. This effect from firm age may also point to changing trends in business organization, with growing entrepreneurial interest over recent years in creating organizations which possess dependent business models that are highly integrated from the outset. Age effects are moreover quantitatively large (Table IV, Panel D). For example, consider the following two B Corps which, apart from their age, take on sample average values of all the other independent variables. The first firm is one year old; the second one is two decades old. The probability that the 1-year old firm has a non-integrated business model is $34 \%$; the probability that it has an integrated business model is $49 \%$. The corresponding probabilities for the 20 -year old firm are $76 \%$ and $13 \%$, respectively. This is a large difference which indicates that new firms are increasingly being founded with integrated $\mathrm{S} \& \mathrm{E}$ missions. That is, the data may be revealing a new entrepreneurial pattern of firm emergence whereby integrated business models are increasingly 'baked in' to organizational structure from the get-go.

Fourth, there are some strong and significant industry effects, which suggest that some industry sectors are more likely than others to host B Corps with integrated business model types. Most notably, recall that the modal industry sector in the sample is 'Consulting, HR and 
Marketing Services', I(Con). This has a large and significant negative association with SEMI values. Computing marginal effects for this industry dummy, 'switching the dummy on' increases the probability of having SEMI $=0$ from $50 \%$ to $95 \%$; decreases the probability of having SEMI $=1$ from $17 \%$ to $3 \%$ and decreases the probability of having SEMI $=2$ from $33 \%$ to $2 \%$. These are sizeable effects.

Similar, but somewhat smaller negative effects are observed for firms in the 'IT, Software and Web Design' and 'Real Estate and Workplace' sectors [I(IT) and I(Re)]. These effects are statistically significant in both Models (1) and (2) in Table III. Other negative impacts are observed for the Financial and Education sectors in Model (1) only. By the very nature of their product or service, firms in some industries may lend themselves more readily to mission integration than firms in others. That is, these industry effects may be a 'natural' outcome of business models forced to be consistent with industry requirements, rather than a situation where firms with intentions to integrate their S\&E and business missions self-select into industries when they decide to do a start-up.

Finally, Model (2) of Table III reports a significant negative association between certification year and the SEMI index. Note that this is not capturing an age effect, since that is controlled for separately. This result therefore implies that firms of a given age which certified more recently have less integrated S\&E missions on average that would be indicative of a nonintegrated business model type. For example, it could be that there is a 'bandwagon effect' at play, whereby firms with less integrated S\&E missions notice that others are getting B Lab certification and apply for it too. However, it should be noted that this effect is somewhat dependent on model specification, since it is not statistically significant in Model (1). 


\section{Discussion}

To date, relatively little scholarly attention has been paid to conceptually categorizing and empirically measuring the degree of business model integration between the social/environmental and financial activities of hybrid organizations. The paper extends earlier work by proposing a three-category typology of the degree of business model integration of commercial organizations that have a social and/or environmental mission, comprising three observable types: non-integrated, partially integrated, and integrated. The paper developed a measure of social-environmental mission integration (SEMI) corresponding to this typology and illustrated the SEMI measure using hand-collected data on a specific type of hybrid organization: Certified Benefit Corporations. Our empirical analysis helped identify salient features of heterogeneity of this type of organization: among the key empirical findings are the following.

First, the modal outcome, even among this subset of hybrid organizations, turned out to be non-integrated S\&E missions. This finding is striking and raises some interesting questions about the potential tradeoffs inherent to hybrid business model types, categorization and legitimacy. For instance, are there relatively few integrated B Corp types because integration is relatively difficult to achieve - so integrated B Corps are less likely to emerge and survive? After all, creating integrated business models might be a challenging task, requiring a great exertion of creativity and originality, and more importantly: hidden costs (Lautermann, 2013).

Alternatively, might the finding that relatively few B Corps have integrated business models suggest that integrated organizations do not need B certification? That could be, for example, because certification makes organizations easier to categorize by stakeholders. Hence for partially integrated and non-integrated organizations, B certification may be a valuable legitimacy and reputation-building mechanism. Some support for this notion comes from the 
further empirical finding that B Lab's B scores are not strongly correlated with SEMI scores. As well as confirming the value of the SEMI as a distinct measure - which captures a potentially useful source of information which is separate from B scores - this finding suggests that many organizations that lack integrated business models and are doing a form of CSR may nevertheless be able to gain external kudos from third-party certifications (Parker et al., 2018). For instance, if most consumers are unaware of company B scores, with only certification itself being observed, then firms may have an incentive to just surmount the certification B score hurdle of 80 . B Corp certification may then enable such firms to 'hide' within a category and reap the advantages of a good collective reputation. While B Corp certification is a badge of honor attached to those firms who want to 'do well by doing good', it is possible that not all B Corps are striving to change the world by passionately focusing on creating S\&E impact (Gehman \& Grimes, 2016). In which case, it may call into question the centrality of the S\&E mission of some B Corps - suggesting that, at the very least, SEMI scores could serve as a valuable additional data point for stakeholders in addition to B scores.

Relating to this point, an additional empirical finding was that B Corps with high 'outward-facing' B score components relating to community and environmental impact were significantly more likely to have business models with integrated S\&E missions. At the same time, B Corps with high 'inward-facing' B score components relating to treatment of workers and governance were no more likely to have business models with integrated S\&E missions. This is interesting because the hidden processes that represent inward-facing aspects of B Corps may be less noticed by external audiences even when large investments are made in these domains. Hence measures taken to promote 'inward-facing' B impact scores, which may be rewarded by the B Assessment, do not translate into deeper integration when using our SEMI 
measure. In contrast, external-facing elements which appeal to consumers and other stakeholders directly appear to be associated with both higher B scores and more integrated business models. Thus, we conjecture that organizations with non-integrated business models and whose social mission is implemented in an internal-facing way may have strong incentives to obtain B Lab certification to signal their mission to third parties. In contrast, certification may be a less pressing imperative for organizations with integrated business models and whose social mission is implemented in an external-facing way. More generally, we suggest that future research on B Corps needs to recognize the importance of disentangling the internal and external aspects of social and environmental impact.

We have deliberately refrained in this discussion from making normative judgments about the social value of integrated vs partially integrated vs non-integrated B Corps. At the time of writing, we lack objective evidence linking SEMI with overall S\&E impact, so we cannot blithely assume that low SEMI scores are associated with irresponsible corporate behavior, disingenuous motivations or purely aspirational efforts to signal social impact (Whiteman \& Cooper, 2016). To the extent that genuine S\&E efforts are being made and are reflected in low SEMI scores, the latter may be construed as relatively 'noisy' signals of mission delivery integrity. Hence an integrated business model might be a target for B Corps to aspire to, if it conveys a relatively clearer signal to external stakeholders than a non-integrated business model. Thus, the present study highlights the need to further understand the sincerity, integrity, and the effectiveness of messages signaled by B Corps to entrepreneurs, investors and customers along with their evaluation of the business model types that operationalize hybridity.

We believe our work also carries several implications for entrepreneurs who are interested in developing business models that deliver on dual missions. First, such entrepreneurs 
may benefit from identifying their degree of SEMI and benchmarking it against those of actual or aspirant rivals. That could inform them about their legitimacy, category membership and mission signaling potential, which could influence how they fashion and transmit messages around their missions. Second, low SEMI scores could also focus attention on their business models and whether they need to be reviewed and possibly amended, to integrate better the economic and non-economic sides of the business. Research on the dynamic analysis of business models is well underway (Cavalcante et al., 2011; De Reuver et al., 2009; Morris et al., 2005), yet to date, the topic of adjusting business models to incorporate a desired degree of S\&E mission integration has not been fully explored in this literature.

Third, the empirical finding that younger firms have more integrated business models on average may carry implications for new start-ups. As noted above, older organizations may find it difficult to change their business models, especially if they are characterized by reputational inertia, defined by professionally designated categories, or belong to strong industrial categories (Paolella \& Durand, 2016). Hence the degree of S\&E mission integration may be an important initial choice at the time new hybrid ventures are founded. 'Imprinting' logic suggests that it may be easier and less costly to integrate social missions at the outset, than to attempt adjusting business models to increase integration once they have been put into place (Moroz et al., 2018). An interesting question that emerges from these findings points to the potential significance of how timing (integrating at start up, nascent, growth or other stages) and the imprinting processes involved may affect the probability of non-integrated firms to seek a more integrated model (including partially integrated models) and the potential success of these types of organizational change (or vice versa). Entrepreneurs would therefore be well-advised to think hard about this aspect of their business model choice at the time they are configuring their new ventures. 
Our work is not without limitations. One important limitation is its reliance on an empirical sample of B Corps. In practice, hybrid organizations are very heterogeneous, comprising not only B Corps but also L3Cs, flexible purpose corporations, community interest companies and social business corporations (among others). In contrast, our sample captures only a 'narrow' selection of hybrid organizations, associated with B Lab certification. As a result, it omits interesting classes of hybrids which are not B Corps. Indeed, one could even go further and ask whether B Corps really represent hybridity, since any firm, including for-profits, can apply for B Corp certification if they fulfill certain conditions. We acknowledge this limitation of the present study and call for future empirical work to replicate our measurement of SEMI using different and possibly more appropriate sampling frames. This could provide validation checks on the sensitivity of our results obtained for B Corps and extend our understanding of how SEMI scores vary for different types of hybrid organization.

\section{Conclusions}

As the growing literature on hybrid organizations attests, integrating social and environmental missions with commercial imperatives remains an ongoing challenge for entrepreneurs and managers. This paper has proposed a new typology which characterizes the degrees to which financial and S\&E missions are integrated within a hybrid organization's business model. Business models may be either integrated, partially integrated, or non-integrated; we went on to propose an associated Social and Environmental Mission Integration (SEMI) measure which was empirically illustrated using a hand-collected sample of 256 North American Certified B Corporations.

Among our empirical findings, several stand out. One is that the B scores from B Lab, 
although a relevant and increasingly popular metric for measuring social performance of B Corps, are not well-suited to help audiences evaluate the extent to which social and environmental missions are integrated with financial aspects of business models. Another is that even among B Corps, which are believed to care about social and environmental issues so strongly that they are willing to incur substantial costs to obtain certification (Parker et al., 2018), most firms have non-integrated business models. This outcome is less pronounced among B Corps with an 'outward-facing' focus on environmental and community issues - as well as among younger B Corps. The modest correlations between B scores and SEMI scores confirm the value of SEMI in providing a distinct source of information which stakeholders can use in their evaluations of these firms. We hope that our work will inform not only entrepreneurs looking to establish and develop new mission-oriented ventures, but also scholars seeking to address challenges arising from conflicting logics in hybrid organizations in general, and B Corps in particular.

\section{References}

André, R. (2012). Assessing the accountability of the benefit corporation: Will this new gray sector organization enhance corporate social responsibility? Journal of Business Ethics, 110(1), 133-150.

Austin, J., Stevenson, H., \& Wei-Skillern, J. (2006). Social and commercial entrepreneurship: same, different, or both? Entrepreneurship Theory and Practice, 30(1), 1-22.

Bacharach, S. B. (1989). Organizational theories: Some criteria for evaluation. Academy of Management Review, 14(4), 496-515.

Battilana, J. \& Lee, M. (2014). 'Advancing research on hybrid organizing-Insights from the study of social enterprises'. Academy of Management Annals, 8(1), 397-441. 
Battilana, J., Lee, M., Walker, J. \& Dorsey, C. (2012). In search of the hybrid ideal. Stanford Social Innovation Review, 10(3), 50-55.

Beddewela, E., \& Fairbrass, J. (2016). Seeking legitimacy through CSR: Institutional pressures and corporate responses of multinationals in Sri Lanka. Journal of Business Ethics, 136(3), 503-522.

B Lab (2017). Website homepage. Available at: https://www.bcorporation.net/ (accessed December 2013).

Cavalcante, S., Kesting, P., \& Ulhøi, J. (2011). Business model dynamics and innovation:(re) establishing the missing linkages. Management Decision, 49(8), 1327-1342.

Corbett, A. \& Katz, J. (2017). Hybrid Ventures: Perspectives \& Approaches to Blended Value Entrepreneurship. In: Advances in Entrepreneurship, Firm Emergence and Growth. Emerald Publishing.

Dacin, P. A., Dacin, M. T., \& Matear, M. (2010). Social entrepreneurship: Why we don't need a new theory and how we move forward from here. Academy of Management Perspectives, 24(3), 37-57.

Dart, R. (2004). The legitimacy of social enterprise. Nonprofit Management and Leadership, 14(4), 411-424.

Davies, I. A., \& Doherty, B. (2018). Balancing a hybrid business model: The search for equilibrium at Cafédirect. Journal of Business Ethics, 1-24.

De Reuver, M., Bouwman, H., \& Maclnnes, I. (2009). Business model dynamics: a case survey. Journal of Theoretical and Applied Electronic Commerce Research, 4(1), 1-11.

Dobrev, S. D., Kim, T. Y. \& Hannan, M. T. (2001). Dynamics of niche width and resource partitioning. American Journal of Sociology, 106(5), 1299-1337. 
Doherty, B., Haugh, H., \& Lyon, F. (2014). Social enterprises as hybrid organizations: A review and research agenda. International Journal of Management Reviews, 16(4), 417-436.

Doty, D. H., \& Glick, W. H. (1994). Typologies as a unique form of theory building: Toward improved understanding and modeling. Academy of Management Review, 19(2), 230-251.

Durand, R., \& Khaire, M. (2017). Where do market categories come from and how?

Distinguishing category creation from category emergence. Journal of Management, 43(1), 87-110.

Durand, R. \& McGuire, J. (2005). Legitimating agencies in the face of selection: The case of AACSB. Organization Studies, 26(2), 165-196.

Durand, R. \& Paolella, L. (2013). Category stretching: Reorienting research on categories in strategy, entrepreneurship, and organization theory. Journal of Management Studies, 50(6), 1100-1123.

Dyllick, T., \& Muff, K. (2016). Clarifying the meaning of sustainable business: Introducing a typology from business-as-usual to true business sustainability. Organization \& Environment, 29(2), 156-174.

Ebrahim, A., Battilana, J. \& Mair, J. (2014). The governance of social enterprises: Mission drift and accountability challenges in hybrid organizations. Research in Organizational Behavior, 34, 81-100.

Emerson, J. (2003). The blended value proposition: Integrating social and financial returns. California Management Review, 45(4), 35-51.

Fiss, P. C. (2011). Building better causal theories: A fuzzy set approach to typologies in organization research. Academy of Management Journal, 54(2), 393-420. 
Gehman, J. \& Grimes, M. (2016). Hidden badge of honor: how contextual distinctiveness affects category promotion among certified B Corporations. Academy of Management Journal, amj-2015.

Glaser, B. G. (1965). The constant comparative method of qualitative analysis. Social Problems, 12(4), 436-445.

Greene, W.H. (2012). Econometric Analysis (7 $7^{\text {th }}$ edition). Boston: Pearson Education.

Hahn, R., \& Ince, I. (2016). Constituents and characteristics of hybrid businesses: a qualitative, empirical framework. Journal of Small Business Management, 54, 33-52.

Haigh, N., \& Hoffman, A. J. (2012). Hybrid organizations: The next chapter of sustainable business. Organizational Dynamics, 41(2), 126-134.

Haigh, N., Walker, J., Bacq, S., \& Kickul, J. (2015). Hybrid organizations: origins, strategies, impacts, and implications. California Management Review, 57(3), 5-12.

Hannan, M. T., Pólos, L. \& Carroll, G. R. (2007). Logics of Organization Theory: Audiences, Codes, and Ecologies. Princeton University Press.

Hiller, J. S. (2013). The benefit corporation and corporate social responsibility. Journal of Business Ethics, 118(2), 287-301.

Hoffman, A. J., Badiane, K. K., \& Haigh, N. (2012). Hybrid organizations as agents of positive social change: Bridging the for-profit \& non-profit divide. Using a positive lens to explore social change and organizations: Building a theoretical and research foundation, $131-153$

Hsu, G., Hannan, M. T. \& Koçak, Ö. (2009). Multiple category memberships in markets: An integrative theory and two empirical tests. American Sociological Review, 74(1), 150-169. 
Jaeger-Erben, M., Rückert-John, J., \& Schäfer, M. (2015). Sustainable consumption through social innovation: a typology of innovations for sustainable consumption practices. Journal of Cleaner Production, 108, 784-798.

Jay, J. (2013). Navigating paradox as a mechanism of change and innovation in hybrid organizations. Academy of Management Journal, 56(1), 137-159.

Kolk, A., \& Lenfant, F. (2016). Hybrid business models for peace and reconciliation. Business Horizons, 59(5), 503-524.

Laufer, W. S. (2003). Social accountability and corporate greenwashing. Journal of Business Ethics, 43(3), 253-261.

Lautermann, C. (2013). The ambiguities of (social) value creation: towards an extended understanding of entrepreneurial value creation for society. Social Enterprise Journal, 9(2), 184-202.

Mair, J., Mayer, J., \& Lutz, E. (2015). Navigating institutional plurality: Organizational governance in hybrid organizations. Organization Studies, 36(6), 713-739.

Markides, C. \& Charitou, C. D. (2004). Competing with dual business models: A contingency approach. The Academy of Management Executive, 18(3), 22-36.

McMullen, J. S. \& Warnick, B. J. (2016). Should we require every new venture to be a hybrid organization?. Journal of Management Studies, 53(4), 630-662.

Ménard, C. (2004). The economics of hybrid organizations. Journal of Institutional and Theoretical Economics JITE, 160(3), 345-376.

Moroz, P., Branzei, O., Parker, S. \& Gamble, E. (2018). Imprinting with purpose: New prosocial opportunities and B Corp certification. Journal of Business Venturing, 33(2), 117129. 
Muñoz, P. \& Kimmitt, J. (2018). Social mission as competitive advantage: A configurational analysis of the strategic conditions of social entrepreneurship. Journal of Business Research, in press.

Morris, M., Schindehutte, M., \& Allen, J. (2005). The entrepreneur's business model: toward a unified perspective. Journal of Business Research, 58(6), 726-735.

Negro, G., Hannan, M. T. \& Rao, H. (2010). Categorical contrast and audience appeal: Niche width and critical success in winemaking. Industrial and Corporate Change, 19(5), 13971425.

Negro, G. \& Leung, M. D. (2013). “Actual” and perceptual effects of category spanning. Organization Science, 24(3), 684-696.

O'Neil, I. \& Ucbasaran, D. (2016). Balancing “what matters to me” with 'what matters to them': Exploring the legitimation process of environmental entrepreneurs. Journal of Business Venturing, 31(2), 133-152.

Pache, A. C. \& Santos, F. (2013). Inside the hybrid organization: Selective coupling as a response to competing institutional logics. Academy of Management Journal, 56(4), 9721001.

Paolella, L. \& Durand, R. (2016). Category spanning, evaluation, and performance: Revised theory and test on the corporate law market. Academy of Management Journal, 59(1), $330-351$.

Parker, S. C., Gamble, E., Moroz, P. W., \& Branzei, O. (2018). The Impact of B Lab Certification on Firm Growth. Academy of Management Discoveries, in press.

Peredo, A. M., Haugh, H. M., \& McLean, M. (2017). Common property: Uncommon forms of prosocial organizing. Journal of Business Venturing, 33(5), 660-678. 
Porac, J. F., Thomas, H., Wilson, F., Paton, D. \& Kanfer, A. (1995). Rivalry and the industry model of Scottish knitwear producers. Administrative Science Quarterly, 203-227.

Rawhouser, H., Cummings, M., \& Crane, A. (2015). Benefit corporation legislation and the emergence of a social hybrid category. California Management Review, 57(3), 13-35.

Reiser, D. B. (2011). Benefit corporations-a sustainable form of organization. Wake Forest Law Review, 46, 591.

Saldana, J. (2009). An introduction to codes and coding. The coding manual for qualitative researchers, 1-31. Sage Publishing.

Santos, F. M. (2012). A positive theory of social entrepreneurship. Journal of Business Ethics, 111(3), 335-351.

Santos, F., Pache, A. C., \& Birkholz, C. (2015). Making hybrids work: Aligning business models and organizational design for social enterprises. California Management Review, 57(3), 36-58.

Teece, D. J. (2010). Business models, business strategy and innovation. Long Range Planning, 43(2), 172-194.

Thomas, D. R. (2006). A general inductive approach for analyzing qualitative evaluation data. American Journal of Evaluation, 27(2), 237-246.

Thompson, J. D. \& MacMillan, I. C. (2010). Business models: Creating new markets and societal wealth. Long Range Planning, 43(2), 291-307.

Thornton, P. H., Ocasio, W., \& Lounsbury, M. (2012). The institutional logics perspective: A new approach to culture, structure, and process. Oxford University Press on Demand.

Tracey, P., \& Stott, N. (2017). Social innovation: a window on alternative ways of organizing and innovating. Innovation, 19(1), 51-60. 
Venkatraman, N. (1989). Strategic orientation of business enterprises: The construct, dimensionality, and measurement. Management Science, 35(8), 942-962.

Vergne, J. P. \& Wry, T. (2014). Categorizing categorization research: Review, integration, and future directions. Journal of Management Studies, 51(1), 56-94.

Weick, K. E. (2012). Organized sensemaking: A commentary on processes of interpretive work. Human Relations, 65(1), 141-153.

Whiteman, G., \& Cooper, W. H. (2016). Decoupling rape. Academy of Management Discoveries, 2(2), 115-154.

Wilson, F. \& Post, J. E. (2013). Business models for people, planet (\& profits): exploring the phenomena of social business, a market-based approach to social value creation. Small Business Economics, 40(3), 715-737.

Zahra, S. A., Gedajlovic, E., Neubaum, D. O., \& Shulman, J. M. (2009). A typology of social entrepreneurs: Motives, search processes and ethical challenges. Journal of Business Venturing, 24(5), 519-532.

Zott, C., \& Amit, R. (2007). Business model design and the performance of entrepreneurial firms. Organization Science, 18(2), 181-199.

Zott, C. \& Amit, R. (2008). The fit between product market strategy and business model: implications for firm performance. Strategic Management Journal, 29(1), 1-26.

Zott, C. \& Amit, R. (2010). Business model design: an activity system perspective. Long Range Planning, 43(2), 216-226.

Zuckerman, E. W. (1999). The categorical imperative: Securities analysts and the illegitimacy discount. American Journal of Sociology, 104(5), 1398-1438. 
Table I. Descriptive Statistics

\begin{tabular}{|c|c|c|c|c|c|c|}
\hline Variable & Description & $\mathbf{N}$ & Mean & & $\%$ & \\
\hline & & & & 0 & 1 & 2 \\
\hline SEMI & SEMI score & 248 & 0.62 & 0.63 & 0.12 & 0.25 \\
\hline Ben-C & Whether a benefit corporation & 249 & 0.06 & & & \\
\hline Non-US & Whether based outside USA & 249 & 0.16 & & & \\
\hline $\mathrm{I}(\mathrm{Con})$ & Industry: Consulting, HR or Marketing & 249 & 0.23 & & & \\
\hline I(IT) & Industry: IT, Software or Web Design & 249 & 0.12 & & & \\
\hline I(Man) & Industry: Light manuf., crafts or apparel & 249 & 0.11 & & & \\
\hline I(Fin) & Industry: Financial services & 249 & 0.12 & & & \\
\hline $\mathrm{I}(\mathrm{Ed})$ & Industry: Education & 249 & 0.03 & & & \\
\hline I(Arch) & Industry: Architecture/Construction & 249 & 0.05 & & & \\
\hline $\mathrm{I}(\mathrm{He})$ & $\begin{array}{l}\text { Industry: Health/fitness, beauty/personal } \\
\text { care }\end{array}$ & 249 & 0.04 & & & \\
\hline \multirow[t]{2}{*}{$\mathrm{I}(\mathrm{Re})$} & Industry: Real estate, workspaces & 249 & 0.04 & & & \\
\hline & & & & $\begin{array}{l}\text { S. } \\
\text { Dev. }\end{array}$ & Min & $\operatorname{Max}$ \\
\hline B Score & B Lab latest overall B score & 310 & 108.21 & 21.77 & 80.00 & 174.16 \\
\hline B Gov & B Lab latest Governance component score & 306 & 15.36 & 6.39 & 0.00 & 58.65 \\
\hline B Wor & B Lab latest Worker component score & 270 & 25.47 & 7.31 & 0.00 & 61.00 \\
\hline B Env & B Lab latest Environment component score & 310 & 21.19 & 17.23 & 0.00 & 83.18 \\
\hline B Com & B Lab latest Community component score & 310 & 41.32 & 21.21 & 0.00 & 106.00 \\
\hline Age & Age of the firm in 2015 & 249 & 12.68 & 11.49 & 1.00 & 67.00 \\
\hline Rev-Gr & Revenue growth rate over previous year & 158 & 0.27 & 0.56 & -3.00 & 4.97 \\
\hline Emp-Gr & Employment growth rate over previous year & 165 & 0.17 & 0.33 & -1.39 & 2.08 \\
\hline Year-C & Year certified minus 2000 & 126 & 12.55 & 1.19 & 10.00 & 15.00 \\
\hline
\end{tabular}

Notes:

$\mathrm{N}$ is the number of firms; $\mathrm{S}$. Dev. is the standard deviation. 
Table II. Correlation matrix

\begin{tabular}{|c|c|c|c|c|c|c|c|c|c|c|c|c|}
\hline & SEMI & B Score & B Gov & B Wor & B Env & B Com & Age & Rev-Gr & Emp-Gr & Year-C & Ben-C & Non-US \\
\hline B Score & $.25^{* * *}$ & & & & & & & & & & & \\
\hline B Gov & -.10 & $.18^{* *}$ & & & & & & & & & & \\
\hline B Wor & -.04 & $.16^{* *}$ & -.00 & & & & & & & & & \\
\hline B Env & $.24 * * *$ & $.16^{* *}$ & -.06 & $-.22 * * *$ & & & & & & & & \\
\hline B Com & -.00 & $.43 * * *$ & .09 & .11 & $-.34 * * *$ & & & & & & & \\
\hline Age & $-.19^{* * *}$ & .09 & -.04 & $.13 *$ & .08 & $-.21 * * *$ & & & & & & \\
\hline Rev-Gr & -.04 & -.05 & .05 & .03 & -.11 & .04 & $-.26 * * *$ & & & & & \\
\hline Emp-Gr & -.02 & -.08 & .03 & -.03 & $-.16^{* *}$ & .05 & $-.24 * * *$ & $.35 * * *$ & & & & \\
\hline Year-C & -.03 & $-.35^{* * *}$ & $-.39 * * *$ & $.21 * * *$ & .04 & .00 & $-.12 * *$ & .07 & $.11^{*}$ & & & \\
\hline Ben-C & -.04 & $.25 * * *$ & .08 & $.28 * * *$ & -.08 & .06 & $.08^{*}$ & -.03 & -.03 & -.05 & & \\
\hline Non-US & $.08^{*}$ & $-.11^{*}$ & .11 & -.04 & .04 & .04 & -.04 & .01 & .06 & .02 & $-.11 * * *$ & \\
\hline I(Con) & $-.28 * * *$ & -.11 & .04 & .01 & $-.24 * * *$ & $.22 * * *$ & -.02 & -.06 & $-.13 * * *$ & -.03 & $.10 * * *$ & -.02 \\
\hline I(IT) & -.02 & -.06 & -.06 & .05 & $-.29 * * *$ & .04 & $-.15 * * *$ & $.13 * * *$ & $.09 *$ & -.06 & -.04 & .01 \\
\hline I(Man) & $.13 * * *$ & -.00 & -.03 & $-.12 *$ & $.41 * * *$ & $-.13^{*}$ & .05 & -.02 & -.01 & -.07 & .02 & .06 \\
\hline I(Fin) & .03 & $.18^{* * *}$ & $.24 * * *$ & .16 & $-.23 * * *$ & .05 & .04 & $-.10 * *$ & $-.08^{*}$ & -.07 & $.07 *$ & -.02 \\
\hline $\mathrm{I}(\mathrm{Ed})$ & $.08 * *$ & -.01 & -.04 & -.00 & $-.12 *$ & .08 & $-.11 * * *$ & .02 & .07 & -.04 & -.05 & -.02 \\
\hline $\mathrm{I}(\mathrm{Arch})$ & -.01 & .11 & .05 & $.13^{*}$ & .02 & -.08 & $.15^{* * *}$ & -.05 & -.01 & .01 & .02 & .01 \\
\hline $\mathrm{I}(\mathrm{He})$ & -.03 & -.09 & -.09 & $-.12 *$ & $.17 * * *$ & $-.18 * * *$ & .06 & -.03 & -.01 & .02 & -.05 & -.02 \\
\hline $\mathrm{I}(\mathrm{Re})$ & $.10 * * *$ & -.03 & -.02 & -.02 & .04 & -.04 & $-.12 * * *$ & $.09 *$ & .01 & .03 & -.05 & .01 \\
\hline
\end{tabular}

Notes:

$* \mathrm{p}<0.05, * * \mathrm{p}<0.01, * * * \mathrm{p}<0.001$ 
Table III. Ordered Probit Results

\begin{tabular}{|c|c|c|}
\hline Explanatory Variable & Model (1) & Model (2) \\
\hline B Score & $\begin{array}{l}0.018 * * * \\
(0.004)\end{array}$ & \\
\hline B Gov & & $\begin{array}{l}-0.016 \\
(0.015)\end{array}$ \\
\hline B Wor & & $\begin{array}{l}0.014 \\
(0.014)\end{array}$ \\
\hline B Env & & $\begin{array}{l}0.020 * * * \\
(0.007)\end{array}$ \\
\hline B Com & & $\begin{array}{l}0.015 * * * \\
(0.005)\end{array}$ \\
\hline Age & $\begin{array}{l}-0.058^{* * *} \\
(0.010)\end{array}$ & $\begin{array}{l}-0.063 * * * \\
(0.011)\end{array}$ \\
\hline Rev-Gr & $\begin{array}{l}-0.125 \\
(0.143)\end{array}$ & $\begin{array}{l}-0.075 \\
(0.159)\end{array}$ \\
\hline Emp-Gr & $\begin{array}{l}-0.483 \\
(0.298)\end{array}$ & $\begin{array}{l}-0.386 \\
(0.318)\end{array}$ \\
\hline Year-C & $\begin{array}{l}-0.004 \\
(0.103)\end{array}$ & $\begin{array}{l}-0.249 * \\
(0.117)\end{array}$ \\
\hline Ben-C & $\begin{array}{l}0.351 \\
(0.368)\end{array}$ & $\begin{array}{l}0.476 \\
(0.395)\end{array}$ \\
\hline Non-US & $\begin{array}{l}0.078 \\
(0.271)\end{array}$ & $\begin{array}{l}-0.089 \\
(0.290)\end{array}$ \\
\hline $\mathrm{I}(\mathrm{Con})$ & $\begin{array}{l}-1.616^{* * *} \\
(0.314)\end{array}$ & $\begin{array}{l}-1.405 * * * \\
(0.371)\end{array}$ \\
\hline I(IT) & $\begin{array}{l}-0.823 * * * \\
(0.294)\end{array}$ & $\begin{array}{l}-0.773 * \\
(0.367)\end{array}$ \\
\hline I(Man) & $\begin{array}{l}-0.338 \\
(0.277)\end{array}$ & $\begin{array}{l}-0.451 \\
(0.321)\end{array}$ \\
\hline I(Fin) & $\begin{array}{l}-0.906 * * * \\
(0.287)\end{array}$ & $\begin{array}{l}-0.520 \\
(0.364)\end{array}$ \\
\hline $\mathrm{I}(\mathrm{Ed})$ & $\begin{array}{l}-0.700 * \\
(0.345)\end{array}$ & $\begin{array}{l}-0.658 \\
(0.380)\end{array}$ \\
\hline I(Arch) & $\begin{array}{l}0.015 \\
(0.580)\end{array}$ & $\begin{array}{l}0.452 \\
(0.604)\end{array}$ \\
\hline $\mathrm{I}(\mathrm{He})$ & $\begin{array}{l}0.150 \\
(0.539)\end{array}$ & $\begin{array}{l}0.001 \\
(0.522)\end{array}$ \\
\hline $\mathrm{I}(\mathrm{Re})$ & $\begin{array}{l}-0.960 * \\
(0.410)\end{array}$ & $\begin{array}{l}-0.965 * \\
(0.472)\end{array}$ \\
\hline $\begin{array}{l}\text { Pseudo-R }{ }^{2} \\
\text { Wald } \chi^{2} \\
\text { Log pseudo-likelihood } \\
\mathrm{N}\end{array}$ & $\begin{array}{l}0.16 \\
74.53 * * * \\
-204.99 \\
266\end{array}$ & $\begin{array}{l}0.17 \\
69.98 * * * \\
-179.90 \\
236\end{array}$ \\
\hline
\end{tabular}

Notes: Dependent variable is SEMI. Robust standard errors in parentheses. ${ }^{*} \mathrm{p}<0.05, * * \mathrm{p}<0.01$, $* * * p<0.001$. Multiple (panel) values of some independent variables account for the sample size of 266 (column (1)) and 236 (column (2)). 


\section{Table IV. Predicted probabilities of SEMI for different B scores}

\begin{tabular}{lccc}
\hline & $(1)$ & $(2)$ & $(3)$ \\
VARIABLES & $\operatorname{Pr}(\mathrm{SEMI}=0)$ & $\operatorname{Pr}(\mathrm{SEMI}=1)$ & $\operatorname{Pr}(\mathrm{SEMI}=2)$ \\
& \multicolumn{3}{c}{ Panel $A}$. \\
Predicted prob. & $0.81^{* * *}$ & $0.10^{* * *}$ & $0.10^{* * *}$ \\
B score $=80$ & $(0.04)$ & $(0.02)$ & $(0.03)$ \\
& & & $0.13^{* * *}$ \\
Predicted prob. & $0.69^{* * *}$ & $(0.02)$ & $(0.03)$ \\
B score $=100$ & $(0.03)$ & $0.16^{* * * *}$ & $0.28^{* * *}$ \\
Predicted prob. & $0.56^{* * *}$ & $(0.03)$ & $(0.03)$ \\
B score $=120$ & $(0.03)$ & & $0.17 * * *$ \\
Predicted prob. & $0.41^{* * *}$ & $(0.03)$ & $(0.05)$ \\
B score $=140$ & $(0.05)$ & &
\end{tabular}

Panel B.

Predicted prob.

$\mathrm{B}$ Env $=0$

Predicted prob.

B Env $=25$

Predicted prob.

$\mathrm{B}$ Env $=50$

Predicted prob.

$\mathrm{B}$ Env $=75$
$0.78 * * *$

$(0.05)$

$0.61 * * *$

(0.04)

$0.41 * * *$

$(0.09)$

$0.23 *$

(0.12)
$0.09 * * *$

(0.02)

$0.13 * * *$

(0.02)

$0.15 * * *$

$(0.03)$

$0.13 * * *$

(0.04)
$0.12 * * *$

(0.04)

$0.26 * * *$

(0.03)

$0.44 * * *$

(0.09)

$0.64 * * *$

(0.15)

Panel C.

Predicted prob.

B Com $=0$

Predicted prob.

B Com $=25$

Predicted prob.

B Com $=50$

Predicted prob.

B Com $=75$
$0.82 * * *$

(0.06)

$0.71 * * *$

(0.04)

$0.57 * * *$

(0.04)

$0.43 * * *$

(0.07)
$0.08 * * *$

(0.02)

$0.10^{* *}$

$(0.04)$

$0.11 * * *$

(0.02)

$0.18 * * *$

$(0.03)$

$0.14 * * *$

(0.03)

$0.29 * * *$

(0.03)

$0.15 * * *$

(0.03)
$0.42 * * *$

(0.07) 
Panel D.
Predicted prob.
$0.34 * * *$
$0.17 * * *$
$0.49 * * *$
Age $=1$
(0.06)
$(0.03)$
(0.06)
Predicted prob.
$0.43 * * *$
Age $=5$
(0.05)
$0.17 * * *$
$0.40 * * *$
(0.03)
(0.05)
Predicted prob.
$0.55 * * *$
$0.16^{* * *}$
$0.29 * * *$
Age $=10$
(0.04)
$(0.03)$
(0.04)
Predicted prob.
$0.76^{* * *}$
$0.11 * * *$
$0.13 * * *$
Age $=20$
(0.03)
(0.02)
(0.02)

Notes: Panel A and D entries calculated using Model (1) of Table III; Panels B and C entries calculated using Model (1) of Table III. All calculations performed using STATA's 'margins' command. Parentheses and asterisks as in Table III. 


\section{Compliance with Ethical Standards}

Funding: This study received no outside funding.

Conflict of interest: The authors declare no conflict of interest.

Ethical approval: All procedures were performed in accordance with the ethical standards of the institutional research committee and with the 1964 Helsinki declaration and its later amendments or comparable ethical standards.

Informed consent: informed consent was obtained from all individual participants included in the study. 